\title{
A Study on Motivational Levels of Teachers in Lhuentse District, Bhutan
}

\author{
Gyeltshen Drukpa
}

Tangmachu MSS, Ministry of Education, Lhuentse, Bhutan

Received: 30 Jul 2021; Received in revised form: 29 Aug 2021; Accepted: 10 Sep 2021

(C)2021 The Author(s). Published by TheShillonga. This is an open access article under the CC BY license (https://creativecommons.org/licenses/by/4.0/)

\begin{abstract}
Many stakeholders in the country describe poor performance of learners is attributed to motivational level of teachers. Principal plays an important role in motivating teacher. This study focuses on factors that impact teachers' motivation in Lhuentse District of Bhutan and on the role of Principal in enhancing teachers' motivation.

Many initiatives have been taken at the Ministry, Department, District and School levels to improve the learning outcomes of students. Tremendous work has been done to achieve a holistic development of the children by infusing the four pillars of Gross National Happiness (GNH), the eight dimensions and seventy-two indicators into the school curriculum. Enormous amount of money and time has been invested for the professional Development programs for the teachers. Principal in school are now seen to take a major role than just a mere administrator. Therefore, qualitative research has further conducted to find out some of the challenges that demoralize teachers professionally and to identify factors that contribute on motivation of teachers in the schools of the District.
\end{abstract}

Keywords-Educational policies, Interventions, Motivation, Professional Development and Teachers'workload.

\section{INTRODUCTION}

Teachers form the backbone of an education system, which is very pivotal for the all-round development of a country. The quality of education in a country hinges on the effort and motivation of teachers and it also contributes in a very significant way for successful learning outcomes of the students. Therefore, success of the schooling system attributes to teachers and their level of motivation which, further has an impact on the classroom transaction and learning outcomes of students.

Motivation is the willingness to do something that should satisfy the needs of the individual. The need that makes certain outcomes appears attractive. From all these perspectives then, there needs to be clear understanding of the relationship between factors affecting teacher morale, motivation and performance.

In schools, teachers are at the forefront in molding the students with knowledge and right values. Therefore, teachers need to be highly motivated to deliver high quality educational services throughout the country. As such, the concern for the declining quality of education in Bhutan can be widely attributed to 'the low motivation of teachers', but it may also be the consequence other factors too. To readdress this situation, government and different stake holders need to come up with certain measures to enhance the motivational level of the teachers. Teachers' interaction with learners is the axis on which educational quality depends, to get the high performing learners with complete vales needs interaction with motivated teachers.

His Majesty the King of Bhutan in his address to the teacher graduates at the $4^{\text {th }}$ Convocation of the Royal University of Bhutan in Paro, January 7, 2012, said

"It is not possible to share what you don't possess so, as teachers, you must yourself be open to new ideas and to learning throughout your lives. Teachers must earn the respect of their students, and inspire them to fulfill their hopes and talents. Look at them as individuals, each with their own talents and unique character. Nurture them to fulfill their potential.

Guide the children to learn to be responsible, even as they experience life 
in all its shades. Keep them on the right path from the start. By high expectations, I mean that teachers must encourage children to aim high and excel. Our children must excel".

The development of a nation in the long run depends on the quality of leaders coming in our education system. Enormous importance has been accorded by the highest authority of the country, to the role of teachers being central for the development and success of children. Therefore having, highlighted the important role that teacher's play to fulfill the aspiration and expectation of children and parents particularly at the school, the principal also plays an equally important role in motivating teachers.

\subsection{Teacher Development Policy.}

In Bhutan, teachers' quality is widely acknowledged to be the key factor influencing the quality of education. Towards the enhancement of teacher morale and motivation, both of which are expected to lead to improved teacher satisfaction and thereby quality, some of the most significant steps taken during $10^{\text {th }}$ Five year plan towards teacher motivation by the Ministry of Education $(\mathrm{MoE})^{1}$ includes the following:

\subsubsection{Human Resource Policies}

Towards enhancing teacher morale and motivation, and as a follow up of Teachers Human Resource Policy, five policy areas: Teacher Career Tracks; Teacher Recruitment; Teacher Performance Management; Teacher Professional Development; and Teacher Deployment, were further developed and endorsed by the 15th Annual Education Conference in December 2011.

\subsubsection{Teacher Incentives}

In order to motivate and incentivize the teaching cadre, the Ministry submitted to the Government a detailed proposal for enhancement of teacher's salary and allowances, including incentives for difficult and remote posting, and teachers required to take up additional responsibilities etc. Therefore, despite of the resource constraints faced by the country, teachers package either in terms of salary revision, house rent allowance and remote posting allowance is to be taken place by the new government in July 2014.

1.1.3. In-service Education of Teachers (INSET) Master Plan and Delivery Strategies

\footnotetext{
${ }^{1}$ Fourth Annual Report of Hon'ble Prime Minister the $9^{\text {th }}$ Session of $1^{\text {st }}$ Parliament, the state of the Nation: Education, 2012
}

Towards the enhancement and effective delivery of relevant and quality professional development programmes, the In-service Education of Teachers (INSET) Master Plan and Delivery Strategies has been completed, following a Needs Assessment Study, intensive stakeholders' workshops, and the development of training modules, handbooks and manuals for training teachers and principals. As part of the development and trial of INSET modules, a total of 1000 teachers and 150 principals covering six Districts were trained.

\subsection{Statement of the Research Problem}

The motivation level amongst teachers can be considered relatively low considering the present trend of teachers leaving the teaching profession. Teacher retention in the system is seen to be a prominent concern in Bhutan. Although the government has made great efforts still the Ministry of Education, is facing a problem of teachers leaving their jobs every year. The number of teachers leaving the teaching job has escalated in Bhutan. Total of 1334 teachers have left the teaching profession from 2008 to 2013 in the last six years either for voluntary retirement, contract expiration, unfortunate events such as death, superannuation and compulsory retirement which translates into $4 \%$ of the total teachers in the country leaving the profession for various reasons (Annual Education Statistics 2013). As such, teachers leaving the teaching force have become an issue of concern. Therefore, if strategic retention plan and policy is not developed timely, shortage of teachers may aggravate which may have an impact on the quality education delivery.

Since a decade, the quality of education has been a burning issue in the country, which was also a topic of discussion amongst the general public and even at the highest decision making bodies of the country, parliament. Overall the falling quality of the standard of education has become a subject of concern to the parents, entire society and the government at large. Various reasons and assumptions were made for the declining standard of education such as poor teaching methodology, low teacher morale and motivation, poor infrastructural facilities, general poor socio- economical background of individual students and lack of qualified teachers.

Annual Status of Student Learning (ASSL) was conducted by Royal Educational Council to test the students of class IV, VI and VIII in English, Mathematics and 
Science in 2011. The report presentation of the ASSL during the $16^{\text {th }}$ Annual Education Conference held in Phuntsholing Higher Secondary School by Department of Curriculum and Research Division (DCRD), Paro shows the low performance of the students comparatively in Lhuentse District in all the three subjects irrespective of classes.

There was concern from the highest government official, the Secretary of the Education pertaining to low student performances in the school that requires the attention for all the policy makers and schools in Lhuentse District. Therefore, since the learning outcomes of the students, the role of the principal and the teacher's motivation are related, the study on the motivation level among the school teachers in Lhuentse District of Bhutan, will help in understanding the factors associated with the low performance. The study will also help in identifying some measures that will help motivate teachers which will impact the performance levels of the students and help not only the District but also the Nation as a whole. This is also done for the partial fulfillment of my International Diploma on Planning Education and Administration.

\subsection{Research Objectives}

The study was conducted keeping in view the following objectives:

1. Identify the main reasons as to why students' performance is poor in Lhuentse District.

2. Examine the teacher motivation levels in Lhuentse District.

3. Identify the main determining factors that motivate teachers in relation to social, economic, cultural and geographic aspects in Lhuentse District.

4. Identify the role of the institution (principal, teacher/staff and students) in motivating teachers.

\subsection{Research Questions}

The research study tried to answer some of the below listed questions:

1. What are the main factors for poor performance of students in Schools in Lhuentse District?

2. Are all teachers satisfied and happy with their teaching profession?

3. What according to the teachers are the Institutional levels factors that can motivate them in their profession?

4. What are the some of the factors that can enhance teacher motivation levels?

\section{METHODLOGY}

The study dealt with both Qualitative and Quantitative research methods, where information was collected from both Secondary and Primary Data

\subsection{Nature of Data}

The primary source of data includes questionnaire, oral and personal observation. This involves gathering data from sample respondents using instrument like survey questionnaire, interview and personal observation.

\subsection{Sampling Method}

Random sampling methods were used for the study. The following steps were undertaken to calculate the sample for the study.

Step 1. All the 14 schools in the Lhuentse District which include Primary, Lower Secondary, Middle Secondary and Higher Secondary Schools were taken for the study as sample schools

Step 2. A list comprising of names of all the teachers from these sample schools were collected which comprises of total 154 teachers.

Step 3. Using the formula given by Taro the sample size for the study was calculated. Out of the total teachers, 111 sample teachers and principals (respondents) were randomly selected using the table of random numbers

Step 4. All the principals of all sample school except one of the middle secondary school were selected as respondents. One of the middle secondary principal of the District were included as the researcher himself happened to be the principal of that school.

\subsection{Data Collection Tools}

Two sets of self-administered questionnaires separately for teachers and principal were used to collect the data for both the teachers and the school. The questionnaire comprised of both closed and open ended questions formulated by the researcher. Research questionnaire for teachers described respondents' background information like gender, age, status education level and length in service, and was describe about the motivational factors based on the Herzberg theory.

Similarly, sample descriptive survey questionnaire was prepared for the school principal too. It described the general information of the school and students' performance. The questionnaire prepared for the school was responded by the Principal. Each set of questionnaire had approximately 20 questions. Teachers were asked to rank some possible job related source of motivational from strongly agree 5,4,3,2 and strongly disagree 1 which will be constructed along a five point Likert type scale. For the 
school, open ended questions are asked to principals. The information collected from both the teachers and principal was later used for qualitative analysis. The respondents were asked to indicate the extent to which they agree the motivational statements provided as a indicator using the scale strongly agree, agree, undecided, disagree, strongly disagree as given below.

\section{Agreement level on Motivational statement \\ Score}

Strongly agree

Agree

Undecided

Disagree

Strongly disagree

The researcher used the Survey questionnaire to minimize the cost and the time for the researcher as the time given for the researcher was very limited to complete the project. Semi Structured Interview was conducted with school Principals of few schools of different levels. However, after interviewing for five Principals, the interviewer limited to five principals as the response was found to be similar.

\subsection{Population and sample size}

\subsubsection{Population}

In the District, there are 13 Community primary schools (CPS), 8 primary schools (PS), 2 Lower Secondary Schools (LSS), 3 Middle Secondary School (MSS) and 1 Higher Secondary Schools (HSS). Total of 3994 students are enrolled in various level of schools. Out of 188 teachers in the District, 140 teachers are teaching in PS, LSS, MSS and HSS (Annual Education Statistics, 2010). The researcher will focus only to the PS, LSS, MSS and HSS. Therefore, total of 140 teachers and 14 principals were the targeted respondent out of which 111 respondents were selected for the research.

\subsubsection{Sample size of respondents}

The Taro Yamane's formula (1967) was used to calculate the sample size. The formula is commonly used in quantitative research in random sampling. Therefore, the sample size is calculated using the formula as given below:

$$
\text { Formula } \mathrm{n}=\mathrm{N} /\left[1+\mathrm{N}(\mathrm{e})^{\wedge} 2\right]
$$

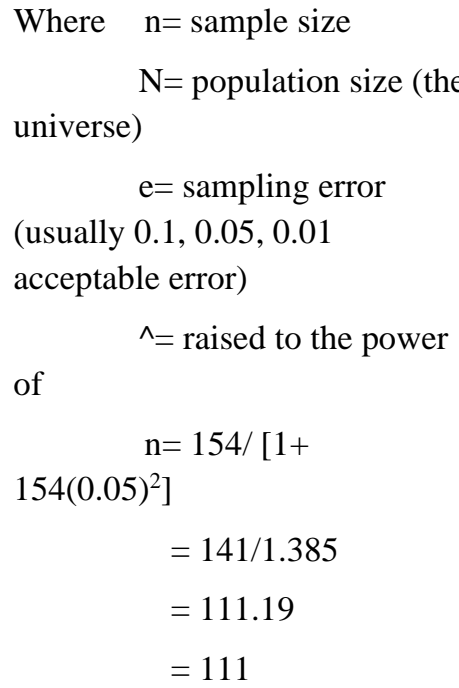

\subsection{Ethical Issues}

In my research, all the formalities were followed before the start of actual data collection. Approval for the collection of the data was obtained from the District commissioner and the District Dy. Education officer. Permission from the concerned principals to conduct research in his/her school was sought. In the study, I requested the principal of each school to distribute and collect back the questionnaire. A written consent was taken from the participants in which letter was sent to each school stating the objectives of my project. It is clearly mentioned in the letter that individual identity will not be revealed. This was done so that to enable the participant to feel comfortable to write their honest opinions. Letter written to the principal is attached as the end as annexure 1.

\subsubsection{Validity}

Walliman \& Bucler (2008) defined validity as "the accuracy of result, whether the collected data representative and illustrate the phenomenon and levels the trueness". To ensure validity of instruments, the instruments were developed under close guidance of the supervisor. After the questions were designed, it was pre tested with ten participants among the teachers from targeted sample schools. This helped to identify ambiguous questions in the instruments which were rephrased and contextually calibrated in achieving the objectives.

\subsubsection{Reliability}

Reliability is the consistency of data (Walliman \& Bucler , 2008). Reliability is the extent to which the measuring instruments will produce consistent scores when the same groups of individuals are repeatedly measured under the same conditions (Amin, 2005). To maintain the quality of the questionnaire, the questionnaire was reviewed through the research advisor and the improvement was made based on the objectives of the research topic. The 
study administered one type of questionnaire to teachers by using Cronbach reliability test; Alpha values of 0.753 were attained implying that the tool is suitable for assessing the effect of motivation on teaching performance.

\subsection{Methods}

During data analysis, descriptive statistics were used in presenting the data collected from the study in order to describe the characteristics of the information of sample by using frequency, percentage, mean and standard deviation. Among the different scales used to measure the data, interval scale was used to measure the data. The interval scale is preferred as Likert scales is used the study and found to be appropriate.

\subsection{Limitations of the Study}

The time allocated to complete the study for the researcher was 3 months, because of the very short time frame of the study period, intensive coverage on taking views of different stakeholders like students and parents could not be collected which otherwise is paramount in such type of research. It would have added more values and insight with their participation. The researcher had to make movement from one school to another. As such, the researchers face some financial constrain as every expenditure incurred for travel and other miscellaneous had to be met from personal expenses.

\section{LITERATURE REVIEW}

\section{Defining for Motivation}

Motivation can be defined as the driving force that causes the flux from desire to will in life. For example, hunger is a motivation that elicits a desire to eat. Motivation is essentially about commitment to doing something. In the context of a business, motivation can be said to be about the 'will to work'. Motivation can come from the enjoyment of the work itself and/or from the desire to achieve certain goals. It can also come from the sense of satisfaction that we gain from completing something, or achieving a successful outcome after a difficult project or problem solved.

Why does motivation matter in teaching? In short, people's behaviour is determined by what motivates them. The performance of employees is a product of both their abilities (e.g. skills \& experience) and motivation. A talented teacher who feels de-motivated is unlikely to perform well at work, whereas a motivated employee can often deliver far more than is expected from them. Similarly some studies pertaining to motivation have been reviewed in the following sections to get a better understanding of motivation and also trying to link these to the present study.
Terrel. $\mathrm{H}$ stated that there are three things to be remembered in education. "The first one is motivation. The second one is motivation. The third one is motivation". Here he also argued that teachers' motivation cannot be used as a synonymous with achievement of students. Therefore, immediate achievement and test performance are determined by variety of other factors. Considering the fact that quality of education has direct relationship with the morale and motivation of teachers, numerous researches has been done in the world (Carole, 1990).

Similarly, various studies have been taken on related issues in Bhutan. The study that was done on morale and motivation of Bhutanese school teachers has fifty-one teachers, with teaching experience between three to thirtyfive years. While doing interview, only three participant shown being happy and positive of the profession. The rest expressed their frustration, dissatisfaction and low morale and motivation (Dorji, 2006). A government agency -centre for education and Research (CERD, 2007), and an autonomous organization- Royal Education council (REC, 2008, $2009 \& 2013$ ) also have taken researches on related issues in Bhutan. Harmer defined motivation as "some kind of internal drive which pushes someone to do things in order to achieve something" (Dorji ,2008).

Similarly, Ryan and Deci (2000) stated that to be motivated means to be moved to do something. Unlike unmotivated people who have lost impetus and inspiration to act, motivated people are energized and activated to the end of a task. Teaching job requires dealing with human mind and intellectuals. It requires patience and commitment. As such, readiness of teaching comes with motivation of individual.

Everad at al (2004) stated that 'if people do not feel committed towards a given result or activity, the only motivation at our disposal are those of carrot and stick'. The statement support to his definition of motivation as getting result through people, therefore, unmotivated teachers can do more harm than good to students learning.

Allan, John (1998) defined motivation as 'the force that drives people to do things once the task has been done, the motivation may disappear' however he defend to his definition that in good management the essential for good management is to make it last and it needs to last through the time at work. In the same vein, motivation of the people in an organization like schools should have long lasting motivation. One time motivation may not have immense benefit to the organization. He also stated that motivation of people depends on the type of leadership leader demonstrate. It is mentioned that people gets motivated when leadership style and style most matches to any situation will depend on situational context. 


\subsection{Teacher Motivation}

Teacher motivation has become an important issue in most of the developing countries given their responsibility to impart knowledge and skills to learners. It is argued that satisfied teachers are generally more productive and can influence students' achievement (Mertler, 1992). Motivated teachers can arouse student's interest in studies. Many teachers have at least two major misconceptions about motivation that prevent them from using this concept with maximum effectiveness. One misconception is that some students are unmotivated. However, as a teacher we need to understand that as long as a student chooses goals and expends a certain amount of effort to achieve them they are considered to be motivated. The second misconception is that one person can directly motivate another. This view is inaccurate because motivation should come from within oneself. In the following chapter discusses the various motivation theories written in different literature.

It is often believed that people in an organization are its most important asset. Therefore, successful leader must make the best use of this asset. Therefore, Leadership is defined as an 'influence process over a group of individual, workers or employees aimed at gaining their commitment to shared values and goals and subsequent goal achievement' Dimmock (2012). He also stated that 'Leadership is a social influence process guided by a moral purpose with the aim of building capacity by optimizing available resources towards the achievement of the shared goals'.

Mukhopadhyay (1994) in her study on motivation in education management pointed that any educational institution, for its survival and progress, motivation of the individual employee and the group, is considered to be the core factor. Other factors, such as individual competencies, attitude towards work, appropriate performance goals, structure of the job, institutional climate, incentive system, career opportunities etc are also responsible for institutional renewal development. Any effort by educational administrators and managers to motivate their employees must take care of all the factors together.

\subsection{Theories of Motivation}

Motivation as a complex concept, numerous theories has been developed to provide the detail overview and understanding of motivation. Mukhopadhyay (1994) has categorized the theories of motivation into the following approaches:

\subsubsection{Dynamic approaches}

This approach is designed based on "unconscious impulse" called as psychoanalysis. In this approach, behavior is determined by multidimensional conflicts such as Id, ego and super-ego which forms the strong force of human psyche. It is stated that people's character is determined by his/her behavior and thus reveals the identity of childhood experiences. As such, unconscious and unnoticed conflict comes in the process of motivation.

\subsubsection{Behavioral Approach.}

In this approach, motivation is viewed as a way of behavior. In this regard Skinner, Bandura \& Mischel stated that behaviorism is determined by reinforcement and modeling which is in turns demined by the intensity and reinforcement of the situational variables. In the same way, Skinner assorted that reinforcement will strengthens behavior of individual of his/her performance of desired behavior. Therefore, to motivate means to reward on doing desired behavior and viz a viz (Mukhopadhyay, 1994).

\subsubsection{Cognitive Approach}

In Cognitive Approach, Vroom and Lawler have come up with Expectancy Theory. It is based on the proportion that motivation is dependent upon a set of goals. Individual set a specific goals and he/she acts with expectation that specific behavior will result in its achievement. Later Porter and Lawler supported the expectancy theory by concluding the relationship that reward for the performance and perceiving nature determines satisfaction in individual. (Mukhopadhyay, 1994)

\subsubsection{Content Approach}

Maslow stated that in content approach, "motivation is process of need drive satisfaction". Therefore, needs arises tension and because of the tension, individual gets motivated to achieve the goal (Mukhopadhyay, 1994).The diagrammatic representation of Maslow motivation process is as follows.

\subsubsection{Attribution Approach}

This approach is based on the attribution that is put forward by the individual for the set of task. Motivation of the individual is determined by how he or she perceives the task. Furthermore, Maslow developed motivational theory based on the humanistic psychology and clinical experiences. $\mathrm{He}$ argued that individual motivational requirement could be ordered as a hierarchy and once the given level of need is satisfied it no longer motivate and next higher level of needs to be activated in order to motivate and satisfy individual (Adair, J .1990).

Equity theory unfolds that unfair treatment for the effort made on their work and achievements makes individuals displeased. The theory states that individuals compare the outcomes they receive within and outside the organization. Such comparisons are made based on the outcome-input ratio. If one person gets higher outcome- 
input ratio than another person, there is inequity amongst the two individuals. Therefore, first person experiences "positive inequity" and the other felts "negative inequity." Hence, Individuals resorts to take variety of action to regain and restore the sense of equity.

Davies (2007) asserted that “teachers' treatment of students is often influences by how administrators treat teachers. Being the object of respectful behavior inclines the recipient to treat others in a similarly respectful manner" in this regard, the way principal treat teachers has reciprocal effect to students. When teachers are treated with respect and dignity by the principal, teachers will feel motivated and can have positive impact in students. Besides curriculum the recruitment of competent teachers, and sustaining their morale and motivation are key elements in ensuring quality of education.

\subsection{International Studies on Teachers' Motivation.}

Weis and Pasley stated that (Whitehead 2013). Motivated teachers require less supervision and are willing to accomplish teaching and learning goals. They accept teaching goals as personal goals. They have a sense of confidence, enjoy teaching, are loyal, and are more committed to education as a whole. In contrast, unmotivated teachers are less apt to achieve their curricular goals, have more student discipline problems, and are less interested in change. With strict evaluation strategies, prodding, clear instructions, and close supervision, they often do a satisfactory job at best.

In support of Whitehead and friends, it is a general trend in all the working places. Similar trend is also prevailing in schools in Bhutan. Generally, we see teachers who are professionally committed are motivated in their job. The delivery of lesson is seen to be efficient. Learning outcome of students is comparatively good. On the other hand, unmotivated teacher requires constant supervision and guidance. They are not efficient and often fail to do the task on time.

Tin, G and et.al (1996) conducted a study in Singapore on what motivates teacher. In their study, 27 highly motivated primary and secondary school teachers in Singapore were subjected to an in-depth interview. Out of the total teachers interviewed, 5 were male and rest 22 was female. The report reveals that female teachers are more motivated than male teachers because female teachers found that teaching matches and accommodates them than other job. One of the factors that motivate for the teachers was also students' performance. The study assertions the existence of positive link exists between teachers' motivation and students' academic performance. Therefore, they found out that many teachers in Singapore took up teaching because they love to work with children.
Alam and Farid (2011) did their study to find the factors affecting motivational level of teachers at secondary school level in Rawalpindi city. They found out that one of the motivations is socio economic status of teacher. The study indicates that only 10 percent teachers could meet the necessities of life whereas 90 percent teachers think that the economic status of life needs to be improved. They think that they received less salary as compared to their work. Therefore, majority of the teachers are in favor of the statement that their teaching is affected due to less salary, which needs to be revised.

A study in India state of Jaipur by Ramachandran (2005) reported that the primary school teacher is doing more difficult work than the middle or secondary level schoolteacher. The primary teacher has to deal with small students, whereas the secondary teacher gets ready student. Teachers also felt unfortunate that they are paid less. Beside the over work load and less remuneration, they are also classified as grade III teachers. The status by the term grade III looks derogatory for the teachers which create dissatisfaction and de-motivation. They also pointed in their report that, principals' role as maintaining disciplines (regular attendance of teachers, functioning and teaching). He admitted that all-pervasive bureaucratic indifference or inability had rubbed off on the school system too, which had little power to do anything about a teacher who refused to teach. The ability of the principal is to provide leadership was constrained by the larger system in which she/he had to function.

In contrast, Sergiovanni (1987) has argued that direct principal leadership is only part of the answer to establishing successful schools or institutions of excellence. The principal plays a key role in building and maintaining leadership density. This enabling leadership is revealed and validated by the principals' intents, attributes and behavior that enable teachers, students and parents to function better on behalf of the school and its purposes, to engage more effectively in the work and play of the schools and to promote and elevate the school's achievement

Farber (2010), in his study stated that to attract greater number of quality people and keep quality professionals, we need to pay quality people to join and stay in this professional. In contrast, some of the country makes the choice to underfund public education. They pour money into national security and in other developmental projects. The country which gives Education a less priority fails to retain the competent teachers which can lead to poor quality education system of the country. In Bhutan, although education is given a high priority in terms of resource allocation, yet we see teachers leaving the job every year. To improve the quality of education, eligibility criteria for 
recruitment of fresh teachers need to be streamlined. Academically high performing candidates join in other profession like doctors and engineer merely looking for the benefit packages. Therefore, the government needs to be recruited those academically competent candidates for teaching with attractive pay packages and other incentives.

We all are very much aware that every day teachers face the challenge of introducing new curricular, assessing students work and managing classrooms. In many situations they also face with challenging student populations that do not actually respond to instructional practices. As mentioned in the above mediated effect model, one of the contributing factor for the students learning outcome is people. Literally in this context, people are referred to teachers. School principal has mammoth task to overcome and faced with how to support teachers to meet these challenges of teachers. No matter whatever the challenges, one of the strategies that the principal may take is to motivate the teachers.

Adair J (1990) stated that "leadership and motivation are like brother and sister. It is difficult to talk of leader who does not motivate others". For a teacher, unlike other job, teaching profession requires lot of patience and understanding. This is all because they need to deal with the human beings. It all happens when he/she is motivated in profession. Motivation may mean those conditions of services that will make them happy with their job and not necessarily having a good salary, promotion and recognition are the only contributing factors that can be played by principal to boost teacher's motivation.

\subsection{Studies on Teachers' Motivation in Bhutan.}

Namgay and Yuden (2013) conducted a study on teachers' job satisfaction at the national level to find out the status of job satisfaction in Bhutan. There were total teachers of 7932 from 652 schools who participated in the studies. The school ranges from early childhood care center to higher secondary level. The study reveals that asymp.sig. (2-sided)P value to be 0.05 (0.00) indicating a strong positive relationship between teacher job satisfaction and teachers morale. They also found out that morale of teachers in their job is high who have attended 51 years and above than compared to the younger generation teachers. Level of high job satisfaction for senior teachers than junior teachers could have attributed because of higher salary and respect from the society and fellow teacher mate. However, in contrast, teachers with PGCE, PGDE and Bed the higher level of professional qualification are found to be fewer jobs satisfied than PTC and ZTC.

Similar studies was conducted in Thimphu District (Drukpa, 2010) and in Paro college of Education (Dorji, 2010).In both the studies, teachers consider the monthly salary package to be low and do not commensurate their workload. Among all, they are not satisfied with some of the other factor like lack of professional opportunities, over workload, professional status and frequent changes in education policy.

According to the research report about $28.5 \%$ of the respondents are willing to join other professions given a chance. Some of the reasons were less opportunity for training, heavy work load, unfavorable working condition (common office), no perks, dry salary, monotonous job and strict code of conduct. He also concluded that, there was a very strong desire of teachers for professional development, qualification up gradation to boost their motivation (Dorji, 2008).

Farber (2010), in his study stated that to attract greater number of quality people and keep quality professionals, we need to pay quality people to join and stay in this professional. In contrast, some of the country makes the choice to underfund public education. They pour money into national security and in other developmental projects. The country which gives Education a less priority fails to retain the competent teachers which can lead to poor quality education system of the country. In Bhutan, although education is given a high priority in terms of resource allocation, yet we see teachers leaving the job every year. To improve the quality of education, eligibility criteria for recruitment of fresh teachers need to be streamlined. Academically high performing candidates join in other profession like doctors and engineer merely looking for the benefit packages. Therefore, the government needs to be recruited those academically competent candidates for teaching with attractive pay packages and other incentives.

Drukpa (2010) conducted a study on job satisfaction of secondary school teachers in Thimphu District of Bhutan. He concluded that Teachers are the main stake holders in imparting quality education. Therefore, when the government revised the salaries for civil servants in Bhutan in 2009, teachers were given additional allowances depending on the number of years they have served. All the civil servants serving in the kingdom were given a pay rise of $35 \%$ flat rate and for teachers, additional $10 \%$ of the basic pay as allowance for beginning teachers and $20 \%$ of the basic pay as allowance serving more than 15 years. The allowance is to be paid over and above the salary with the intention to promote higher performance, improved efficiency and meritocracy in the system so that the teachers will be motivated and satisfied. 


\section{MAIN FINDINGS AND ANALYSIS OF THE STUDY}

\section{Introduction}

This chapter presents the main findings, analysis and interpretation of the data that has been collected through survey questionnaires, interview and field notes for the study area which was Lhuentse District of Bhutan.

\subsection{Demographic Profile}

Total of 99 teachers and 12 principals responded for the study from 14 schools. School level ranges from Primary, lower Secondary, Middle Secondary and Higher
Secondary Schools. Out of 99 teacher participants, 77\% were male and $23 \%$ were female. Although most of the schools have contract and NIIT instructors, to get authentic and reliable information only the regular teachers were selected as participants of the research. Out of the 12 Principals who participated in the research, 5 of them were involved in filling up the survey questionnaire and also interviewed using the semi structure interview questionnaire. The semi structure interview questionnaire covered other aspect of the question which was not actually covered in the survey questionnaire

\subsection{Percent of participants by gender}

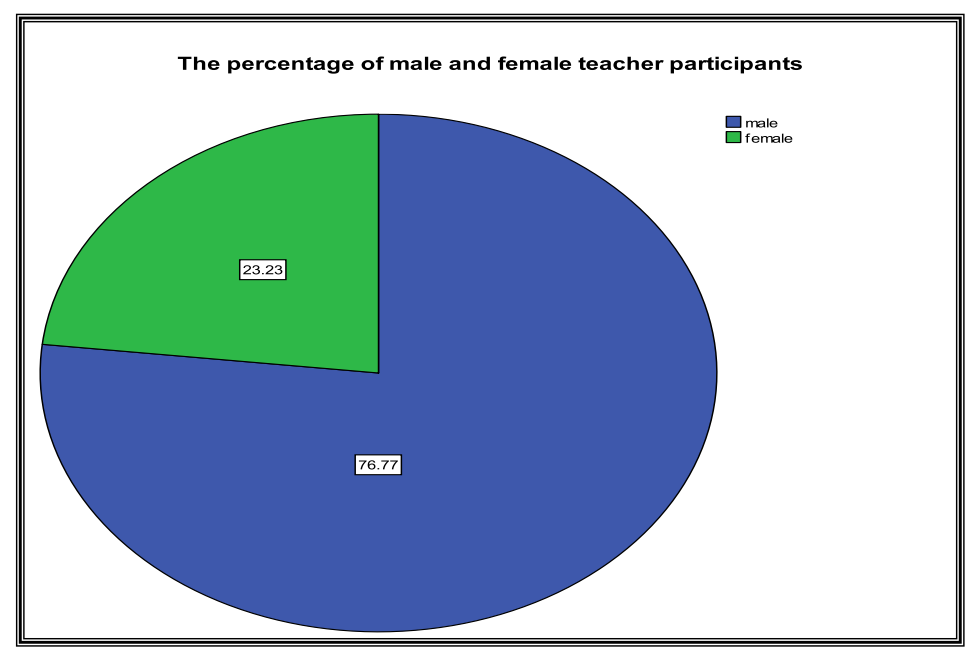

Fig:1. Percent of participants

Out of 111 participants of 14 schools, 45 participants were from Primary, 14 from Lower Secondary, 28 from Middle Secondary and 24 from Higher Secondary. Maximum number of teachers participated from Primary
School as comparatively more number of schools was from primary school level.

\subsection{Geographical Locations of Schools}

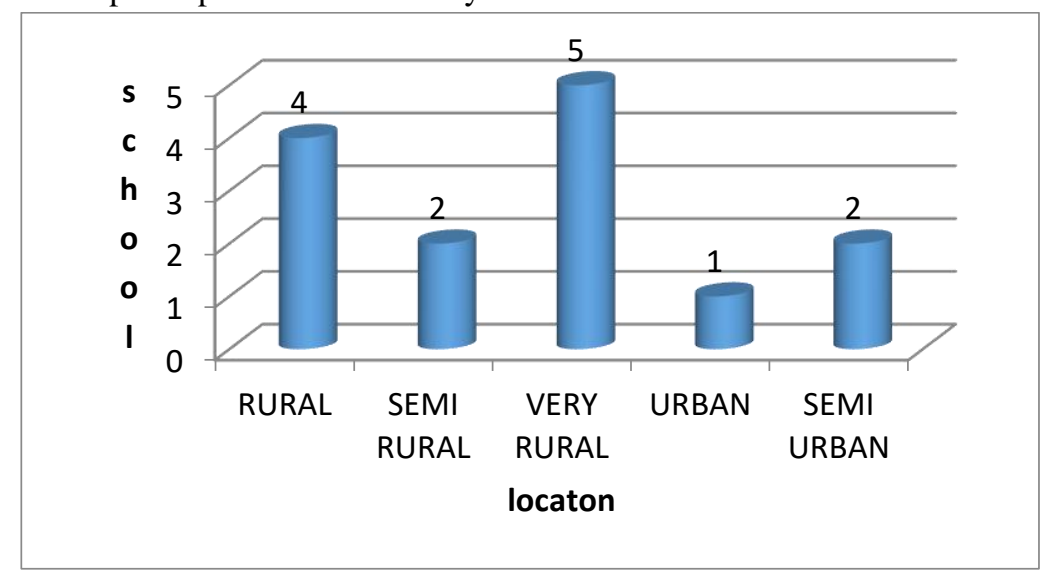

Fig: 2. The figure shows the location of the schools

Out of 14 schools, majority of the responded were from very rural schools. Only one of the schools was located in an urban area. 
4.3 Count of schools having adequate teachers.

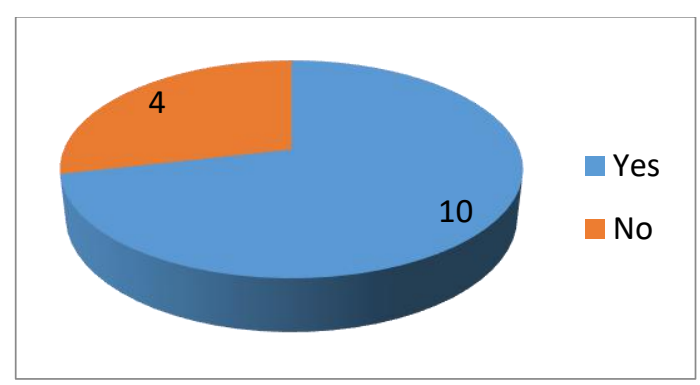

Fig:3. Chart shows that school has adequate teachers as per the requirement

The figure shows the adequacy of teachers in the schools. It is found that majority of the schools have adequate teachers as per the teacher deployment policy of the Ministry. However, few of the schools still have challenges of teacher shortage.

Out of 99 teachers participated for the study, $63 \%$ of the participants has a qualification of Becholar in Education (BED), 25\% had the qualification of Post Graduate Degree in Education (PGDE)and 6\% each of primary teaching certificate and Master in Education. The figure on qualification of teachers' indicate high number of PGDE and BED as the course is offered primarily in the country for teachers who wish to take teaching profession. Primary Teacher Certificate is found to be minimal as the course has stopped in the country. None of the teacher participants have attended doctorate qualification.

\subsection{Interview with Principals}

I had visited five schools and interviewed the Principals of all the five schools. I spent about 8-10 minutes with each participant for interview. All the principals that I have interviewed happened to be male participants. The participants working experience as principal are presented below. Principal of each school are indicated as P1, P2, P3, P4 \& P5 respectively.

\subsection{Principals opinion on teachers' motivational level:}

Majority of the principals had a view that $50 \%$ of the teachers in the schools are motivated. They said that around half of the total teachers in the school are motivated. However, only one principal pointed out that all the teachers are motivated to work.

\subsection{Principal's view on challenges faced by the teachers.}

Principals were asked about the hardship that the teachers faced and to specifically point out the most challenging hardship faced by the teachers. The maximum answers that were provided by most of the participants were the teachers work load and poor remuneration. Most of the participants felt that teachers have to do maximum number of work and receive very minimal salary. They found out the mismatch between the work and benefit they receive. Therefore, some of the findings that was made by Dorji (2006) for decline of teacher morale like heavy workload, poor remuneration showed the strong correlation in this study also.

\subsection{Factors that contribute to improve teachers' motivation.}

Principal were asked to suggest some of the ways to boost teachers' motivation. Majority of the principals felt the requirement of continuous professional development (PD). They also reported that although the professional development programs takes at the school level (SBIP) as per the government policy only less number of teachers get motivated with such program happened in the school level. Therefore as pointed out by Namgay (2013) "the rush is because of the knowledge and skills they gain from such PD programs while at the same time there are financial incentives through travel allowance claim".

\subsection{Recommendations made by the Principals to District Education Sector in their effort to motivate teachers.}

It is impressive to note that all the principal participants reported Professional Development (PD) program a high priority to motivate teachers. They strongly felt that teacher will get motivated if more and frequent PD organized. Similarly, majority opted for basic facilities like house, computer, and recognition as the second priority to improve teachers' motivation.

\subsection{Factors attributed to low test rating of students in Annual Status of Students learning in 2008 and 2011 (ASSL)}

The Annual Status of Student Learning (ASSL) conducted by Royal Education Council (REC) in 2008 and 2011 in three subjects like Mathematics, Science and English indicated low student test score in Lhuentse District. The above mentioned factors were responded by the Principal participant in this research paper. Most of the participants felt that poor English language competency could be the major factors which impede students test score. Similarly lack of teacher competency in teaching mathematics and parental support and care are another factor that contributes in low test score in ASSL. Interestingly, none of the participants pointed out that low performance of students is because of low motivation and commitment of teachers.

\subsection{Teacher's view on profession}

Teachers' were asked to rate on how they view their profession. Majority of the teachers felt that the teaching profession to be much challenging and 
competitive. Both male and female significantly appears to view their profession as competitive and challenging.

Teachers were asked to rate their view on level of job satisfaction. They were asked to rate how teaching gives them job satisfaction. From the figure below it appears that job satisfaction level of $2 \%$ is "strongly high" $6 \%$ of teachers are undecided, $5 \%$ of teachers are satisfied while $96 \%$ of teachers have rated low job satisfaction.

Figure 4.4 Teachers' job satisfaction

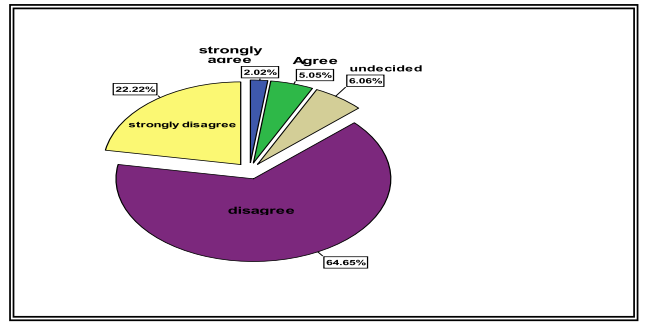

Fig:4. Figure shows the job satisfaction level

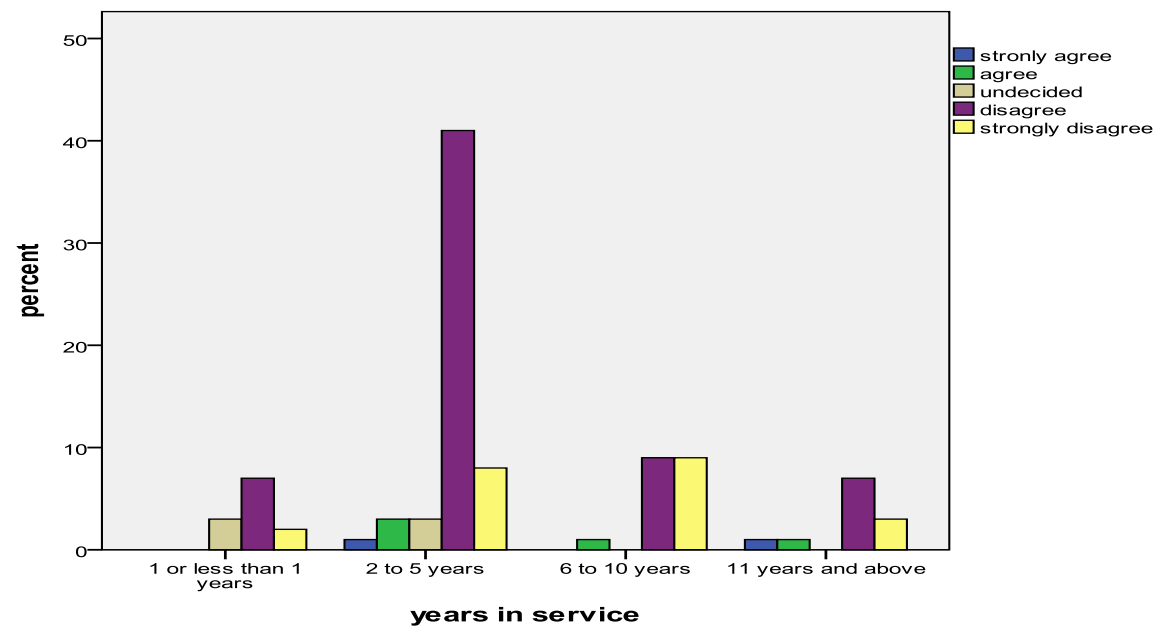

Fig:5. Teacher job satisfaction by years in service

As seen in the figure 5, teachers who have the work experience of 2 to 5 years foresee high prospects for career development in the teaching profession. However, in contrast the beginner teacher and the teachers who have served more than 10 years in teaching services showed significantly low rating on career development in teaching profession.

Teachers were asked to rate on how satisfied they with the kind of support and cooperation provided by the fellow colleagues. In contrast to low level of job satisfaction indicated before, $88 \%$ percent of teachers are motivated to their profession as they find their colleagues to be supportive and helpful. It shows that only $12 \%$ of the teachers have no impact on motivation by fellow colleagues. It can be concluded here that supportive friend is imperative in motivating teachers.
The figure below also indicates the job satisfaction level of teachers by number of years in service. In the figure it is evident that teachers who are new and have only served for 2 to 5 years have shown very low level of job satisfaction. This finding also supplement the finding of Namgay (2013), that younger teachers being only moderately satisfied. There also appear a significantly less number of beginner teachers who have served less than 1 year showing low level of job satisfaction.

\subsection{Teacher job satisfaction by number of years in service}


teachers are not motivated because of the lack of the support and professionalism shown by the Principals.

\subsection{Support form Principal}

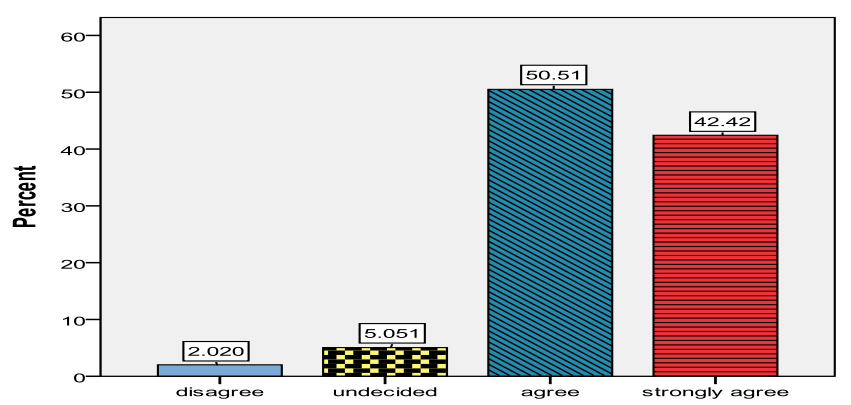

Fig:8. Impact of Principal on teachers' motivation

Teachers were asked if it is enough to cater the basic needs with the monthly salary that they draw every month. The figure given below represent that the salary that teachers receive is not adequate to meet the basic needs for both the male and female teachers. They rated that it is not enough to cater the basic need. As such McKinsey's (2007) study on "How the world's best-performing school system comes on the top" is hereby reconfirmed that good salary package is one of the important motivating factors for the teachers.

\subsection{Monitory satisfaction of teachers}

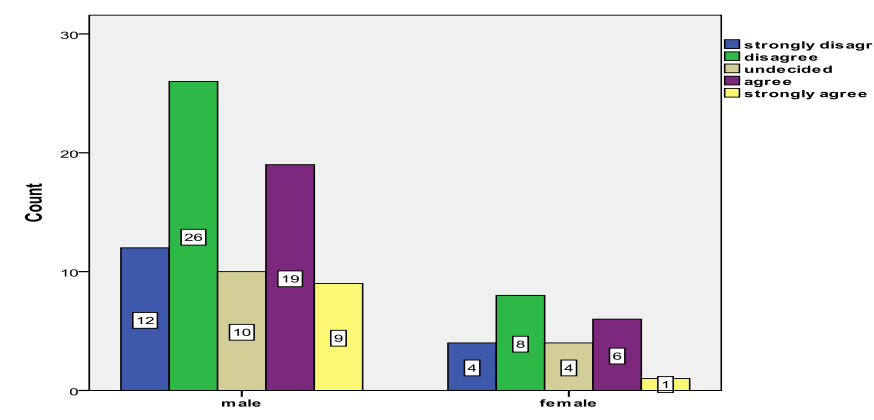

Fig: 9. Teachers' satisfaction level of their salary by gender.

Opinions of the teachers were taken regarding how satisfied they are with the existing transfer policy implemented by the ministry. Happiness level of $4 \%$ of teachers is strong, $28 \%$ average, $23 \%$ not happy and $12 \%$ strongly not happy. This all makes up $50 \%$ of teachers happy and $50 \%$ of the teachers seem to be unhappy. Therefore, transfer policy of the ministry could not be used in this paper for deciding the motivational level of the teachers in the District.

\section{CONCLUSION AND RECOMMENDATIONS}

\subsection{Summary of main findings}

Some of the specific recommendations of this research study have been summarized as follows:

1.Teachers in the District felt and belief that the teaching profession in general to be competitive and challenging.

2.Majority of the teachers who have served for more than 10 years in service foresee themselves of having very less opportunity in career development in teaching profession. This is in contrast to the assumption that was made in research work of Namgay \& Yuden (2013).

3.Significant impact of friends and colleagues has been found in the study on teachers' motivation. About $88 \%$ of the teachers were found to be motivated in their profession as they find their friends to be supportive and helpful.

4.Majority of the new teacher were found to have low satisfaction level of profession. The novice teachers who have been in the system for less than 1 year and those teachers who have served for 2 to 5years showed low job satisfaction.

5. Principal in school plays a crucial role in teachers' motivation. More than 90 percent of the teacher in the District participated in the study feel satisfied and motivated as they receive support and feel their principals to be professional.

6.Many educational researches conducted in the past has recommended the need for salary rise of teachers considering the work load and the time teacher spent in the school. The recent salary revision in general has not made much difference on teachers' salary package as the rise of salary was made uniformly across the ten Ministries. Therefore, considering the nature of work, it is now high time to contemplate and rethink for the policy makers and the politicians and to review the salary package of the teachers.

7. Secondary school teacher seems to be satisfied with the workload of teaching and additional responsibilities that they take in the schools. However, teacher teaching in primary school indicate dissatisfaction of profession because of overloaded teaching periods and additional responsibility that they take in the school. Over workload and dissatisfaction lead to lack of zeal and enthusiasm in teaching. Therefore, some of the professional duty like store in-charge, librarian and office assistant could be relieved for teachers and may be taken up by separate personals. Otherwise, sufficient teacher need to be deployed in primary schools to ease heavy work load of teachers. 


\subsection{Roles of School and School leadership}

Although recognition and award system to the teachers has been initiated from the highest authority of the country the King, it is important to institute the similar award system at the District level and the school level to motivate teachers.

Principal has an important role to encourage and support teachers when ever teachers come up with initiative and new ideas. Principal as a role model equally motivates teacher in the work place. It is equally important for the Principals to be judicious while assigning role and responsibilities. Similarly, schools need to be fair and just in nominating teachers for any kind of in-service and exservice training. Schools need to explore and have sufficient teachers so that the workload would be shared. At the school level, schools have to create a strong culture of team work to retain and motivate teachers. It is encouraging to provide enough PD programs to enhance teachers' skills and knowledge. It is also equally important to provide teachers with adequate teaching learning materials to motivate teachers.

\subsection{Ministry Level}

Ministry should explore more opportunities for teachers both for ex-country and in-country trainings. It should involve all stakeholders in decision making process especially in framing policies. Raise salaries of teachers to motivate teachers. Similarly, it is immensely important to reconsider and review the existing teaching allowance of teachers. In the same vein, monetary incentives for those teachers who have never availed leave of any kind needs to me looked upon and paid. Some of the recommendations also include improvement of the basic amenities like house, water and sanitation of teachers especially in remote schools to make their work place comfortable and conducive for working.

\subsection{Official Reprimand}

All institutions have their own set of rules and ethical obligations that the people working in it need to adhere to. Similarly, a school has its norms which the professional teachers need to adhere professionally. It is found that official reprimand system in school need to be reinforced. It helps the teachers to improve him/her ethically. However, it is always important to orient policy guidelines to teachers by clearly stating the roles and expectation of the teachers.

\subsection{Conclusion}

Similar research could be conducted to understand the in-depth study on motivational level of teachers of the District. It would enable to identify the deeper understanding on motivation of teachers and appropriate support could be provided from the relevant stakeholders to enhance the motivational level of the teachers.

Unlike in this study, number of the respondents and schools for the study could be increased. This will enable researches like this to get the diverse view and perception by including parents and local leaders. The data and some of the information of this study could be used as a baseline to carry out the similar studies in near future. Above all, much advance methods and technology could be used in generating and analyzing the data to give the final finding in precision way.

\section{ACKNOWLEDGMENTS}

My sincere gratitude goes to Dr. Suman Negi, who has always inspired and guided me on completion of this research paper. Without her tireless, unwavering and continuous support, this paper might not have come to this shape. She has been my epitome and inspiration during the whole course of writing this paper which was very instrumental. I remain highly indebted for her who has been my immediate supervisor in writing this paper.

I am equally indebted to my friend Mr. Karma.T, who continuously supported and guided me in writing this paper. I will always cherish his positive comments in paving the road towards the successful completion of this paper. My utmost thanks also goes to Hon'ble Commissioner of the District and all the officials under the District Education officer for their continuous and invaluable support and for their recommendation for the nomination in this program. My sincere thanks go to all the school principals and teachers of Lhuentse District for rendering their help in fruitful collection of data. I would also like to extend my heartfelt gratitude to some of the support staffs of Tangmachu MSS who helped me in the time of need. Finally, I would like to thank to my parents and family who were always there for their love, encouragement and support.

\section{REFERENCES}

[1] A,Carole. (1990).Teacher college record volume 91,number 3,spring 1990.Collumbia University:01614681/90/9103/409\$1.2510

[2] Annual Education Statistics (2013), Royal Governmenrt of Bhutan: Policy and Planning Division,Ministry of Education.

[3] A, John. (1998).Motivating people. New Delhi: Kogan Page India Private Limited.

[4] Adair,J. (1990).Understanding Motivation.England:The Talbot Adair Press.

[5] Alam,M \& Farid,S.(2011).Factors Affecting Teachers Motivation.USA:Foundation University college of Liberal 
Arts and Science.Vol.2 No.1

[6] Davies, Brent. (2007). Developing Sustainable Leadership.New Delhi: SAGE Publication Inc.

[7] Dimmock, C. (2012).Leadership,Capacity Building and School Improvement. New York:CPI Antony Rowe, Chippenham,Wiltshere.

[8] Dorji (2010).Job Satisfaction of Secondary School Teachers in Thimphu District of Bhutan. Research paper.

[9] Dorji,K.(2008).Quality of Education in Bhutan,Research Papers.Paro:CERD, Paro college of Education, Royal University of Bhutan.

[10] Dorji, R. (2006). Teacher Morale and Motivation in Teaching. Unpublished, Paro College of Education,Bhutan.

[11] Everard, K,M \& Wilson, I,.(2004). Effective school management. New Delhi: Sage publication India Pvt. Limited.

[12] Farber,K. (2010). Why great teachers quit and how we might stop the exodus. New Delhi:SAGE Asia-Pacific Pvt.Ltd.

[13] Fourth Annual Report of Hon'ble Prime Minister the $9^{\text {th }}$ session of $1^{\text {st }}$ parliament, the state of the Nation: Education, 2012.

[14] M,B. (1994). Motivation in Educational Management. New Delhi: Sterling Publishers Private Limited.

[15] Mckinsey \& Company (2007).How the world's most improved school system keep getting better,Mckinsey \& Company, Education.

[16] Namgay \& Yuden (2013).Teachers' Job Satisfaction in Bhutan. Royal Education council, Ministry of Education,Bhutan

[17] Ramachandran,V and Pal,M.(2005).Teacher Motivation in India. Jaipur: Education Resource Unit.

[18] Robertson,J,. \& Temperley,H,. (2011).Leadership and learning. New Delhi: SAGE publication India Pvt Ltd.

[19] Sergiovanni, T. (1987). The principalship: a reflective practice perspective: Massachussetts AlIen and Bacon.

[20] Teacher Human Resource Policy (2014).Ministry of Education. Thimphu Bhutan.

[21] Tin,G \& et.al (1996). What Motivates Teachers?: National institute of Education, Nanyang Technological University, Singapore. 